\title{
Repeatability of total Keratometry and standard Keratometry by the IOLMaster 700 and comparison to total corneal astigmatism by Scheimpflug imaging
}

\author{
Giacomo Savini $\mathbb{1}^{1} \cdot$ Leonardo Taroni ${ }^{2} \cdot$ Domenico Schiano-Lomoriello $\mathbb{C}^{1} \cdot$ Kenneth J. Hoffer $\mathbb{C}^{3,4}$
}

Received: 21 June 2020 / Revised: 4 September 2020 / Accepted: 19 October 2020 / Published online: 2 November 2020

(c) The Author(s), under exclusive licence to The Royal College of Ophthalmologists 2020

\begin{abstract}
Objectives We aimed (1) to assess the repeatability of Total Keratometry (TK) and standard keratometry (K) measurements, as provided by the IOLMaster 700 (Carl Zeiss Meditec), and (2) to compare the corneal astigmatism measured by TK to the total corneal astigmatism (TCA) measured by a Scheimpflug camera (Pentacam AXL, Oculus).

Methods Two groups of patients were prospectively enrolled: Group A included previously unoperated eyes undergoing cataract surgery, and Group B eyes with previous myopic corneal excimer laser surgery. TK and $\mathrm{K}$ were measured three times by the same examiner. Repeatability was assessed based on the within-subject standard deviation $\left(S_{\mathrm{w}}\right)$, test-retest variability, coefficient of variation and intraclass correlation coefficient (ICC). In Group A, TCA was measured once and compared to TK astigmatism. Vector analysis was performed according to Næser.

Results In Group A (69 eyes) the mean K and TK were, respectively, 43.14 \pm 1.37 D and 43.18 \pm 1.37 D. In Group B (51 eyes) the mean $\mathrm{K}$ and TK were, respectively, $40.14 \pm 2.20 \mathrm{D}$ and $39.71 \pm 2.35 \mathrm{D}$. The repeatability of the average $\mathrm{K}$ and TK was high $\left(S_{\mathrm{w}}<0.10 \mathrm{D}\right)$. All measurements revealed an ICC $>0.9$. For most measurements the variance of K and TK did not show any statistically significant difference either within groups or between groups. Vectors $\mathrm{KP}(45)$ were significantly different between TK astigmatism and TCA.

Conclusions TK measurements offer high repeatability in unoperated and post-excimer laser surgery eyes. TK astigmatism and TCA measurements could not be considered interchangeable.
\end{abstract}

\section{Introduction}

Keratometry $(\mathrm{K})$ has been traditionally calculated by means of the keratometric index, which enables us to estimate the dioptric power of the whole cornea from measurements of the anterior corneal surface only [1]. More recently, Scheimpflug cameras have allowed us to measure the curvature of the posterior corneal surface as well, resulting in a more accurate calculation (rather than

Giacomo Savini

giacomo.savini@fondazionebietti.it

1 I.R.C.C.S. - G.B. Bietti Foundation, Rome, Italy

2 S.Orsola-Malpighi University Hospital, University of Bologna, Bologna, Italy

3 Stein Eye Institute, University of California, Los Angeles, CA, USA

4 St. Mary’s Eye Center, Santa Monica, CA, USA just an estimation) of total corneal power (TCP). Several studies, however, have demonstrated that TCP by Scheimpflug cameras is lower than the value given by standard K [2-8]. This discrepancy has limited its adoption for intraocular lens (IOL) power calculation, since specifically calculated optimized IOL constants would be required in order to adjust for differences [2].

In 2019 a new approach was offered by the IOLMaster 700 (Carl Zeiss Meditec, Jena, Germany), which can calculate Total Keratometry (TK) from both corneal surfaces and adjust this value so that, on average, it does not differ from standard $\mathrm{K}$ in normal unoperated eyes. TK has been investigated by a few authors for IOL power calculation accuracy in patients undergoing cataract surgery with or without toric IOLs and in eyes with previous corneal refractive surgery [9-12]. However, two issues have not yet been assessed and this paper aims to clarify them. Our goals were as follows: (1) to measure the repeatability of TK as compared to standard $\mathrm{K}$ measurements in previously unoperated eyes undergoing cataract 
surgery and in eyes with previous myopic corneal laser surgery and (2) to compare corneal astigmatism measured by TK to the total corneal astigmatism (TCA) measured by a Scheimpflug camera in patients scheduled for cataract surgery.

\section{Methods}

\section{Patients}

This was a prospective case series. The study protocol was approved by the Ethics Committee of G.B. Bietti Foundation IRCCS, Rome, Italy and complied with the tenets of Declaration of Helsinki. All patients gave their informed consent.

Two groups were enrolled:

- Group A included a consecutive series of unoperated eyes undergoing cataract surgery;

- Group B included a consecutive series of eyes that had undergone either myopic PRK or femtoLASIK and were visited for a routine postoperative examination;

Both Groups were used to assess the repeatability of $\mathrm{K}$ and TK. Moreover, in Group A we investigated agreement between TK astigmatism and TCA measured by a Scheimpflug camera (Pentacam AXL, Oculus, Wetzlar, Germany). Exclusion criteria were as follows: a history of corneal disease or trauma, contact lens use in the past month, a previous diagnosis of keratoconus, suspect keratoconus or dry eye and any kind of ocular surgery (other than excimer laser in Group B).

\section{Instruments}

The IOLMaster 700 (software version 1.80), whose technology is based on swept-source optical coherence tomography (SS-OCT), was used to measure K and TK. With each scan, the device automatically acquires $3 \mathrm{~B}$ scans of the cornea in 6 meridians, so that 18 measurements are taken altogether. Standard K is derived from 15 telecentric measurements of three rings, whose diameter varies slightly depending on the corneal curvature (for an average cornea with a radius of $7.7 \mathrm{~mm}$, they are $\sim 1.5$, 2.5 , and $3.3 \mathrm{~mm}$ ). The average values obtained with this method are systematically identical to those taken at $2.5 \mathrm{~mm}$ with the IOLMaster 500. In the event of poor consistency among the three rings, with deviations from the inner, middle, and outer zones, a warning is shown (or the measurement is not displayed). The 1.3375 keratometric index was selected. As regards the posterior corneal curvature, the IOLMaster 700 first builds a toric anterior surface model from the telecentric 3-zone $\mathrm{K}$ and then measures pachymetry using SS-OCT in the six meridians. The pachymetry values are fitted to the anterior surface model to create the toric posterior surface model. The TK is calculated from the anterior and posterior corneal curvatures, as well as corneal thickness, by means of a thick lens formula. The TK values are adjusted with a proprietary method to match, on average, the $K$ values, so that existing IOL calculation formulas and IOL constants can be adopted with no changes. For both K and TK, we recorded the powers of the flat and steep meridians, their average and their difference, i.e., the measured corneal astigmatism.

The Pentacam AXL (software version 1.21r43), which was used to measure the TCA, is a rotating Scheimpflug camera combined with partial coherence interferometry [13]. TCP and astigmatism are calculated by ray tracing through the anterior and posterior corneal surfaces [4]. In order to facilitate the comparison between the two devices, we selected the measurements centered on the corneal vertex and investigated those with a diameter of 2.0 and $3.0 \mathrm{~mm}$. We analysed both the "ring" and "zone" measurements: the former provide curvature data along the 2.0 and $3.0 \mathrm{~mm}$ rings, whereas the latter also include information about the area within the measured ring.

\section{Measurement procedures}

Each device was brought into focus, and the eye was aligned along the visual axis by means of a central fixation light. Patients were asked to blink before each measurement. Both instruments were calibrated at the beginning of each day.

In order to assess the repeatability of $\mathrm{K}$ and TK measurements by the IOLMaster 700, three repeated consecutive measurements were acquired by one experienced examiner in both groups. The patients were asked to sit back after each measurement, and the device was realigned before the subsequent measurement. We checked that no alerts (!) had been displayed by the instrument software in order to assure the good quality of the measurements.

With the rotating Scheimpflug camera, only one measurement was taken, on condition that the quality specification was acceptable. In Group A, the order sequence of the devices was established at random.

\section{Astigmatism analysis}

Vector analysis was performed according to Næser [14], who described two equations for converting net corneal astigmatism in conventional script notation $(M$ at $\alpha)$ into 
polar values:

$$
\begin{aligned}
& \mathrm{KP}(0)=M \times \cos (2 \times \alpha), \\
& \mathrm{KP}(45)=M \times \sin (2 \times \alpha),
\end{aligned}
$$

where $\mathrm{KP}(0)$ and $\mathrm{KP}(45)$ are, respectively, the polar value along the zero and the 45 degree meridians, $M$ is the astigmatism magnitude and $\alpha$ is the orientation of the steep meridian. Polar values can be used to calculate the average or the difference of any corneal astigmatism; the resulting values can be reconverted to the conventional notation using the following equations:

$$
\begin{aligned}
& \text { Magnitude }=\sqrt{\mathrm{KP}(0)^{2}+\mathrm{KP}(45)^{2}} . \\
& \text { Angle }=\arctan \left(\frac{M-\mathrm{KP}(0)}{\mathrm{KP}(45)}\right)
\end{aligned}
$$

Using Eqs. 1-4 it was possible to compare the mean TCA measured by the Scheimpflug camera to the mean corneal astigmatism by TK (first measurement only). For this purpose, only eyes with $\mathrm{KA}>0.5 \mathrm{D}$ in all three measurements by the IOLMaster 700 were analyzed (as previously done by Ventura et al.) [15], since eyes with a lower astigmatism magnitude are unlikely to undergo toric IOL implantation and are known to display larger variability in astigmatism axis measurements [16, 17]. Moreover, in order to better investigate the difference in corneal astigmatism between $\mathrm{K}$ and $\mathrm{TK}$, a third group (Group $\mathrm{A}_{1}$ ) of unoperated eyes with $\mathrm{KA}>0.5 \mathrm{D}$ was enrolled (with the same exclusion criteria of Group A). This group underwent one measurement only and was not used to test the repeatability.

Vector analysis was carried out separately in eyes with with-the-rule astigmatism (WTR, steep corneal meridian between $60^{\circ}$ and $120^{\circ}$ ), against-the-rule astigmatism (ATR, steep corneal meridian between $0^{\circ}$ and $30^{\circ}$ and between $150^{\circ}$ and $180^{\circ}$ ) and oblique astigmatism (for the remaining orientations of the steep meridian).

\section{Statistical analysis}

Statistics were analyzed by means of MedCalc (version 12.3.0.0, MedCalc Software Ltd, Ostend, Belgium).

The analysis of repeatability was conducted according to the standards of the International Organization for Standardization [18], as recently reported for a similar study by our group [19]. Repeatability was assessed on the basis of intrasession test-retest variability, the coefficient of variation (COV), and the intraclass correlation coefficient (ICC).
The following methods were used:

(1) Intrasession test-retest variability (also known as repeatability or limits of repeatability). This was calculated by multiplying the pooled within-subject SD $\left(S_{\mathrm{w}}\right)$ by 2.77 [20]. Based on repeatability, we can expect that the difference between two measurements for the same subject will be less than $2.77 S_{\mathrm{w}}$ for $95 \%$ of paired observations.

(2) COV. This was calculated as $S_{\mathrm{w}}$ divided by the mean of the measurements and expressed as a percentage. The COV was not calculated for parameters with both positive values and negative values (e.g., $\mathrm{KP}(0)$ and $\mathrm{KP}(45))$ [21].

(3) ICC. This is the ratio of the between-subjects variance to the sum of the pooled within-subject variance and the between-subjects variance. The ICC, which approaches 1.0 when there is no variance between repeated measurements, was automatically calculated using the two-way mixed model and absolute agreement. ICCs ranging from 0 to 1 are classified as follows: ICC less than $0.75=$ poor agreement; ICC 0.75 to less than $0.90=$ moderate agreement and ICC 0.90 and more $=$ high agreement [22].

The variances of $\mathrm{K}$ and TK values were compared in both Groups with the $F$-test for variances. Linear regression was used to analyze the relationship between the difference $\mathrm{K}-\mathrm{TK}$ and the value of $\mathrm{K}$ as well as between astigmatism magnitude and COV.

Based on the article by McAlinden [23], a minimum sample size of 43 eyes was estimated for the two groups used to assess repeatability: this sample size allowed us to have a 0.15 confidence in the estimate with three repeated measures. Actually, since we enrolled slightly larger samples, a 0.12 confidence in the estimate was calculated for Group A and 0.14 for Group B. These values are similar to or higher than those previously reported by other authors investigating the repeatability of corneal topographers, tomographers and keratometers [24-26].

\section{Results}

The analysis of repeatability was performed on 69 unoperated eyes of 69 consecutive patients (mean age: $68.8 \pm 11.9$ years; 38 females) and 51 post-excimer laser surgery eyes of 51 consecutive patients (mean age: $40.9 \pm 11.4$ years; 31 males). In Group $\mathrm{A}$ the mean $\mathrm{K}$ and the mean TK (first measurement only for both values) were, respectively, 43.14 $\pm 1.37 \mathrm{D}$ and $43.18 \pm 1.37 \mathrm{D}$; the mean of the differences between $\mathrm{K}$ and TK was statistically ( $p=0.0006)$ but not clinically significant. 
Table 1 Repeatability analysis of K and TK measurements provided by the IOLMaster 700.

\begin{tabular}{|c|c|c|c|c|c|c|c|c|}
\hline & \multicolumn{4}{|c|}{ Unoperated eyes } & \multicolumn{4}{|c|}{ Post-excimer laser surgery eyes } \\
\hline & $S_{\mathrm{w}}(\mathrm{D})$ & Repeatability (D) & $\operatorname{COV}(\%)$ & $\mathrm{ICC}$ & $S_{\mathrm{w}}(\mathrm{D})$ & Repeatability (D) & $\operatorname{COV}(\%)$ & $\mathrm{ICC}$ \\
\hline \multicolumn{9}{|l|}{ Keratometry } \\
\hline $\mathrm{K}$ flat & 0.10 & 0.27 & 0.23 & 0.995 & 0.08 & 0.23 & 0.21 & 0.999 \\
\hline K steep & 0.11 & 0.30 & 0.25 & 0.994 & 0.10 & 0.28 & 0.25 & 0.999 \\
\hline $\mathrm{K}$ ave & 0.08 & 0.22 & 0.18 & 0.997 & 0.07 & 0.20 & 0.18 & 0.999 \\
\hline $\mathrm{K}$ astigmatism magnitude ${ }^{\mathrm{a}}$ & 0.13 & 0.36 & 9.96 & 0.984 & 0.09 & 0.24 & 9.99 & 0.956 \\
\hline $\mathrm{K}$ astigmatism axis $^{\mathrm{a}}$ & 4.57 & 12.66 & 4.53 & 0.992 & 4.87 & 13.49 & 5.06 & 0.961 \\
\hline $\mathrm{K}$ vector $\mathrm{KP}(0)^{\mathrm{a}}$ & 0.13 & 0.37 & - & 0.986 & 0.10 & 0.28 & - & 0.967 \\
\hline $\mathrm{K}$ vector $\mathrm{KP}(45)^{\mathrm{a}}$ & 0.14 & 0.38 & - & 0.976 & 0.13 & 0.36 & - & 0.927 \\
\hline \multicolumn{9}{|l|}{ Total Keratometry } \\
\hline TK flat & 0.11 & 0.29 & 0.25 & 0.994 & 0.09 & 0.26 & 0.24 & 0.999 \\
\hline TK steep & 0.12 & 0.32 & 0.26 & 0.993 & 0.11 & 0.31 & 0.28 & 0.999 \\
\hline TK ave & 0.09 & 0.24 & 0.20 & 0.996 & 0.09 & 0.24 & 0.22 & 0.999 \\
\hline TK astigmatism magnitude ${ }^{\mathrm{a}}$ & 0.14 & 0.38 & 10.30 & 0.982 & 0.10 & 0.29 & 15.27 & 0.955 \\
\hline TK astigmatism axis ${ }^{\mathrm{a}}$ & 5.02 & 13.90 & 4.72 & 0.991 & 7.68 & 21.28 & 8.32 & 0.961 \\
\hline TK vector $\mathrm{KP}(0)^{\mathrm{a}}$ & 0.14 & 0.39 & - & 0.985 & 0.12 & 0.33 & - & 0.959 \\
\hline TK vector $\mathrm{KP}(45)^{\mathrm{a}}$ & 0.15 & 0.41 & - & 0.973 & 0.13 & 0.36 & - & 0.939 \\
\hline
\end{tabular}

$S_{\mathrm{w}}$ within-subject standard deviation, $C O V$ coefficient of variation, $I C C$ intraclass correlation coefficient.

${ }^{a}$ Astigmatism values were calculated only for eyes with a $\mathrm{K}$ astigmatism magnitude $>0.50 \mathrm{D}$ in all three measurements $(n=38$ unoperated eyes; $n=29$ post-excimer laser surgery eyes).

The difference between the two corneal power calculation methods ( $\mathrm{K}$ minus $\mathrm{TK}$ ) ranged from -0.27 to $+0.26 \mathrm{D}$ and was not correlated to the magnitude of $\mathrm{K}(p>0.05)$. In Group $\mathrm{B}$, the mean $\mathrm{K}$ and the mean TK were, respectively, $40.14 \pm$ $2.20 \mathrm{D}$ and $39.71 \pm 2.35 \mathrm{D}$; the mean of the differences between $\mathrm{K}$ and TK was statistically $(p<0.0001)$ and clinically significant, as it revealed that $\mathrm{K}$ overestimates corneal power compared to TK. The difference between the two corneal power calculation methods $(\mathrm{K}-\mathrm{TK})$ ranged from -0.06 to $+0.88 \mathrm{D}$ and was correlated to the magnitude of $\mathrm{K}$ ( $\left.r=-0.6230 ; r^{2}=0.3881 ; p<0.0001\right)$, thus suggesting that flatter corneas had a higher difference between $\mathrm{K}$ and $\mathrm{TK}$.

\section{Repeatability analysis}

Table 1 shows the test-retest variability, COV and ICC for K and TK. All values revealed high repeatability with $\mathrm{ICC}>0.9$; astigmatism measurements were slightly less repeatable, even if we limited their analysis to cases in which the $\mathrm{K}$ astigmatism was $>0.50 \mathrm{D}$ in all three measurements. Table 1 shows two interesting results. First, the repeatability of TK values is very close to that of $\mathrm{K}$ values in both unoperated corneas and post-excimer laser surgery corneas. Second, the repeatability of $\mathrm{K}$ and TK measurements does not get worse, but slightly improves in eyes with previous excimer laser surgery.

Table 2 shows the results of the variance ratio $F$-test performed to compare the repeatability of $\mathrm{K}$ and $\mathrm{TK}$
Table 2 Variance ratio ( $p$ value), as calculated by means of the $F$-test, between $\mathrm{K}$ and TK.

\begin{tabular}{lll}
\hline & Unoperated corneas & $\begin{array}{l}\text { Post corneal laser } \\
\text { surgery }\end{array}$ \\
\hline K vs TK flat & $1.2280(p=0.399)$ & $1.1616(p=0.598)$ \\
K vs TK steep & $1.1519(p=0.561)$ & $2.3460(p=0.003)$ \\
K vs TK ave & $1.1426(p=0.584)$ & $1.4691(p=0.177)$ \\
K vs TK astigmatism & $1.0775(p=0.826)$ & $1.2325(p=0.463)$ \\
magnitude & & \\
K vs TK & $1.3984(p=0.312)$ & $3.8583(p<0.001)$ \\
astigmatism axis & & \\
K vs TK vector KP $(0)$ & $1.4911(p=0.229)$ & $1.4427(p=0.347)$ \\
K vs TK vector KP & $1.0888(p=0.797)$ & $1.0663(p=0.869)$ \\
$(45)$ & &
\end{tabular}

Astigmatism values were calculated only for eyes with a $\mathrm{K}$ astigmatism magnitude $>0.50 \mathrm{D}$ in all 3 measurements $(n=38$ unoperated eyes; $n=29$ post-excimer laser surgery eyes).

within each sample. It may be observed that for most measurements the variance of $\mathrm{K}$ and $\mathrm{TK}$ did not show any statistically significant difference, the only exception being the measurements of the steep corneal meridian and the axis of TK astigmatism in post-excimer laser surgery eyes.

Table 3 shows the results of the $F$-test performed to compare the repeatability of $\mathrm{K}$ and $\mathrm{TK}$ between unoperated eyes and post-excimer laser surgery eyes. It shows the lack of 
statistically significant differences for most measurements; a few exceptions were observed for TK, where the variance of the steep and the average corneal power and the variance of the astigmatism axis was higher in post-excimer laser group (although these differences are clinically negligible, as Table 1 shows).

Table 3 Variance ratio ( $p$ value) as calculated by means of the $F$-test.

\begin{tabular}{lll}
\hline & Keratometry & Total Keratometry \\
\hline $\begin{array}{l}\text { Flat corneal } \\
\text { meridian power }\end{array}$ & $1.4963(p=0.136)$ & $1.5818(p=0.091)$ \\
$\begin{array}{l}\text { Steep corneal } \\
\text { meridian power }\end{array}$ & $1.0361(p=0.904)$ & $2.6084(p<0.001)$ \\
Average corneal power & $1.5031(p=0.118)$ & $1.9325(p=0.012)$ \\
Astigmatism magnitude & $1.6111(p=0.154)$ & $1.0321(p=0.878)$ \\
Astigmatism axis & $1.9735(p=0.069)$ & $5.0216(p<0.001)$ \\
Vector KP(0) & $1.3177(p=0.419)$ & $1.1612(p=0.601)$ \\
Vector KP(45) & $1.2555(p=0.501)$ & $1.2202(p=0.572)$ \\
\hline
\end{tabular}

Astigmatism values were calculated only for eyes with a $\mathrm{K}$ astigmatism magnitude $>0.50 \mathrm{D}$ in all 3 measurements $(n=38$ unoperated eyes; $n=29$ post-excimer laser surgery eyes).

\section{Astigmatism analysis}

In Group A, the repeatability of the measurement of the $\mathrm{K}$ astigmatism magnitude tended to improve as the magnitude of astigmatism increased $\left(r=-0.5065, r^{2}=0.2565, p<\right.$ 0.0001 , Fig. 1a); this holds true for TK astigmatism in unoperated eyes $\left(r=-0.5279, r^{2}=0.2786, p<0.0001\right.$, Fig. 1b), K astigmatism in post-refractive surgery eyes $(r=$ $-0.4895, r^{2}=0.2396, p=0.0002$, Fig. 1c) and TK astigmatism in post-refractive surgery eyes $\left(r=-0.5563, r^{2}=\right.$ 0.3094, $p<0.0001$, Fig. 1d).

Due to the lower repeatability in eyes with a lower astigmatism magnitude, as previously stated, we performed a more detailed analysis in unoperated eyes whose $\mathrm{K}$ astigmatism magnitude was $>0.5 \mathrm{D}$. This analysis was carried out in eyes of Group $\mathrm{A}$ and Group $\mathrm{A}_{1}$ (the latter included 83 eyes of 83 patients with a mean age of $60.6 \pm 19.9$ years) and involved 40 eyes with ATR astigmatism, 59 eyes with WTR astigmatism and 22 eyes with oblique astigmatism. As expected, in ATR eyes TK astigmatism (1.37 D @ $176.7^{\circ}$ ) was higher than $\mathrm{K}$ astigmatism $\left(1.08 \mathrm{D} @ 175.3^{\circ}\right)$, whereas in WTR eyes TK astigmatism

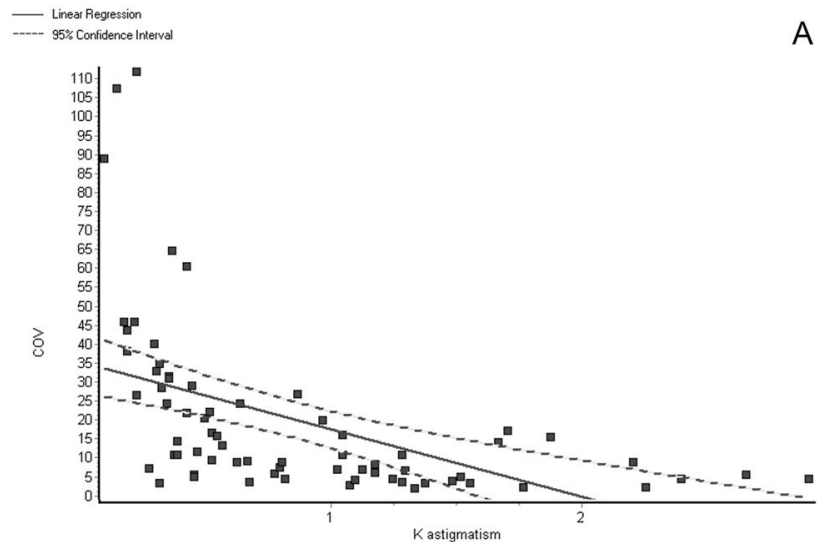

A - Linear Regression
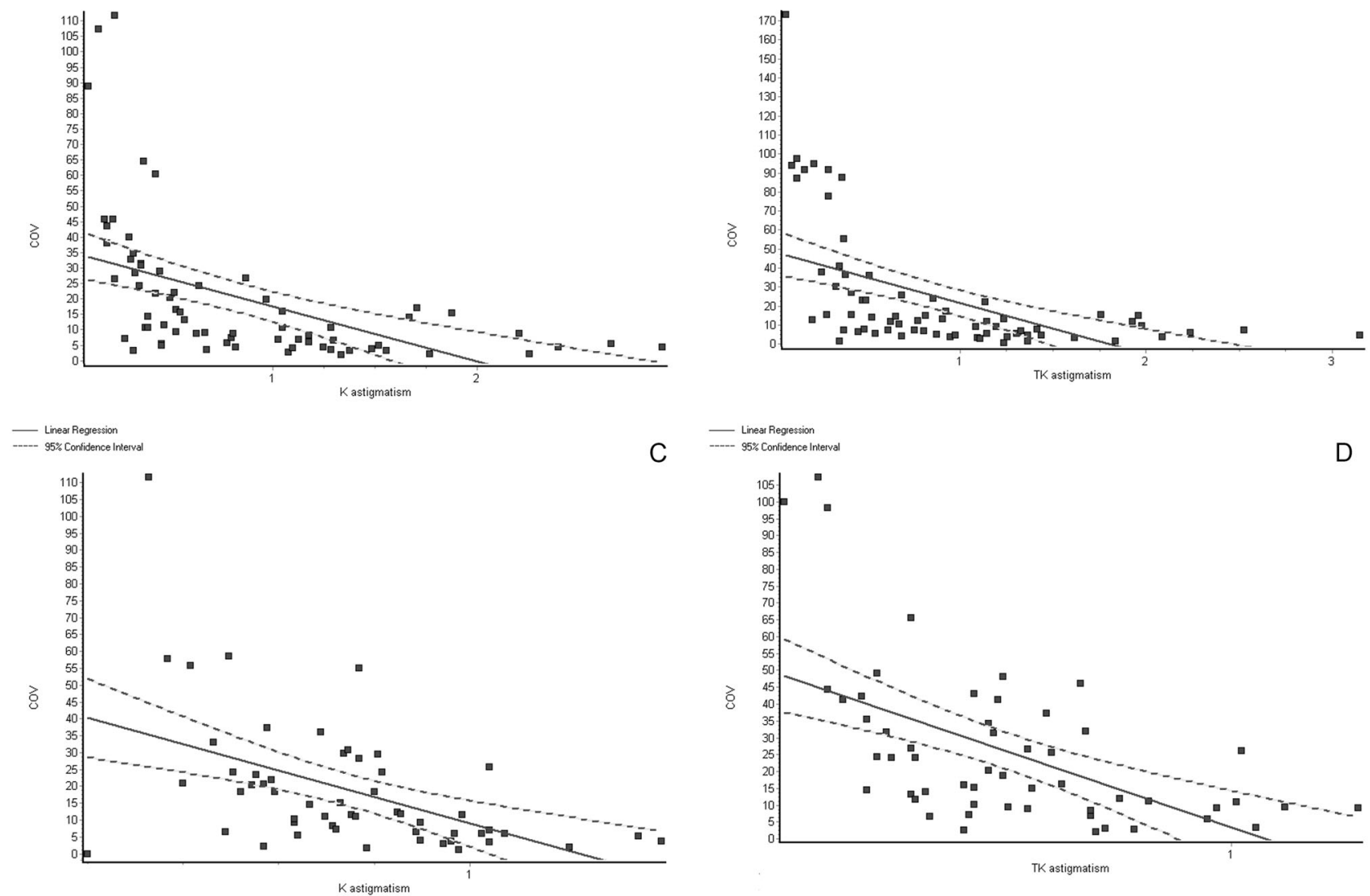

Fig. 1 Linear regression between the coefficient of variation (COV) and the magnitude of astigmatism. A K astigmatism in unoperated eyes. B TK astigmatism in unoperated eyes. C K astigmatism in post-refractive surgery eyes. D TK astigmatism in post-refractive surgery eyes. 
Table 4 Mean net astigmatism values of total corneal astigmatism measured by TK and Scheimpflug imaging.

\begin{tabular}{|c|c|c|c|c|c|}
\hline & $\begin{array}{l}\text { Total } \\
\text { Keratometry }\end{array}$ & $\begin{array}{l}\text { Scheimpflug } \\
2 \mathrm{~mm} \text { zone/apex }\end{array}$ & $\begin{array}{l}\text { Scheimpflug } \\
3 \mathrm{~mm} \text { zone/apex }\end{array}$ & $\begin{array}{l}\text { Scheimpflug } \\
2 \mathrm{~mm} \text { ring/apex }\end{array}$ & $\begin{array}{l}\text { Scheimpflug } \\
3 \mathrm{~mm} \text { ring/apex }\end{array}$ \\
\hline \multicolumn{6}{|c|}{ Against-the-rule astigmatism } \\
\hline Mean astigmatism & $1.32 \mathrm{D} @ 172.8^{\circ}$ & 1.03 D@177.8 & 1.14 D@173.7 & $1.11 \mathrm{D} @ 175.2^{\circ}$ & $1.26 \mathrm{D} @ 170.7^{\circ}$ \\
\hline \multicolumn{6}{|c|}{ With-the-rule astigmatism } \\
\hline \multicolumn{6}{|l|}{ Oblique astigmatism } \\
\hline Mean astigmatism & $0.16 \mathrm{D} @ 62.5^{\circ}$ & $0.25 \mathrm{D} @ 68.6^{\circ}$ & $0.20 \mathrm{D} @ 67.6^{\circ}$ & $0.21 \mathrm{D} @ 66.7^{\circ}$ & $0.12 \mathrm{D} @ 73.2^{\circ}$ \\
\hline
\end{tabular}

Table 5 Mean vectorial values of total corneal astigmatism measured by TK and Scheimpflug imaging.

\begin{tabular}{|c|c|c|c|c|c|c|}
\hline & Total Keratometry & $\begin{array}{l}\text { Scheimpflug } \\
2 \mathrm{~mm} \text { zone/apex }\end{array}$ & $\begin{array}{l}\text { Scheimpflug } \\
3 \mathrm{~mm} \text { zone/apex }\end{array}$ & $\begin{array}{l}\text { Scheimpflug } \\
2 \mathrm{~mm} \text { ring/apex }\end{array}$ & $\begin{array}{l}\text { Scheimpflug } \\
3 \mathrm{~mm} \text { ring/apex }\end{array}$ & $P$ value (ANOVA) \\
\hline \multicolumn{7}{|c|}{ Against-the-rule astigmatism } \\
\hline $\mathrm{KP}(0)$ & $1.28 \pm 0.55$ & $1.03 \pm 0.96$ & $1.11 \pm 0.74$ & $1.09 \pm 0.83$ & $1.20 \pm 0.63$ & n.s. \\
\hline $\mathrm{KP}(45)$ & $-0.37 \pm 0.53$ & $-0.08 \pm 0.60$ & $-0.25 \pm 0.43$ & $-0.18 \pm 0.44$ & $-0.40 \pm 0.47$ & 0.0376 \\
\hline \multicolumn{7}{|c|}{ With-the-rule astigmatism } \\
\hline $\mathrm{KP}(0)$ & $-1.08 \pm 0.63$ & $-1.30 \pm 0.62$ & $-1.22 \pm 0.64$ & $-1.15 \pm 0.69$ & $-1.18 \pm 0.66$ & n.s. \\
\hline $\mathrm{KP}(45)$ & $0.07 \pm 0.62$ & $-0.10 \pm 0.55$ & $-0.10 \pm 0.52$ & $-0.12 \pm 0.49$ & $-0.15 \pm 0,48$ & 0.0242 \\
\hline \multicolumn{7}{|c|}{ Oblique astigmatism } \\
\hline $\mathrm{KP}(0)$ & $-0.07 \pm 0.44$ & $-0.18 \pm 0.74$ & $-0.14 \pm 0.67$ & $-0.14 \pm 0.66$ & $-0.10 \pm 0.66$ & n.s. \\
\hline $\mathrm{KP}(45)$ & $0.12 \pm 1.35$ & $0.17 \pm 1.32$ & $0.14 \pm 1.32$ & $0.15 \pm 1.31$ & $0.07 \pm 1.27$ & n.s. \\
\hline
\end{tabular}

(1.16 D @ 91.0 $)$ was lower than K astigmatism (1.35 D @ $\left.91.8^{\circ}\right)$; a small difference was observed also in eyes with oblique astigmatism $\left(\mathrm{TK}=0.08 \mathrm{D} @ 66.0^{\circ}, \mathrm{K}=0.25 \mathrm{D}\right.$ @ $\left.89.5^{\circ}\right)$. Accordingly, the analysis of the first measurement showed that the vector $\mathrm{KP}(0)$ was higher with TK than with $\mathrm{K}$ in ATR eyes $(1.36 \pm 0.64$ vs. $1.09 \pm 0.64, p<0.0001)$, in WTR eyes $(-1.16 \pm 0.92$ vs $-1.34 \pm 0.89, p<0.0001)$, and in eyes with oblique astigmatism $(-0.00 \pm 0.60 \mathrm{vs}-0.20 \pm$ $0.59, p<0.0001)$. No statistically significant differences were obtained for $\mathrm{KP}(45)$ in any subgroup, meaning that there were no axis differences between $\mathrm{K}$ and $\mathrm{TK}$ astigmatism.

The comparison between TK astigmatism and TCA as measured by the Scheimpflug camera (which was possible in 35 out of 38 eyes due to a low quality of Scheimpflug measurements in 3 eyes) revealed that the measurements provided by the two technologies are not interchangeable (Table 4). In ATR eyes $(n=14)$, the mean TK astigmatism was higher than any TCA measurement. In WTR eyes $(n=$ 10 ), the mean TK astigmatism was lower than any TCA measurement. In eyes with oblique astigmatism $(n=11)$, the mean TK astigmatism was slightly lower than all TCA measurements, but TCA at $3 \mathrm{~mm}$ apex/ring. Overall, the $3 \mathrm{~mm}$ apex/zone by the Scheimpflug camera gave the lowest difference between TK astigmatism and TCA in eyes with ATR astigmatism (0.09 D @ 10.9 $)$ and oblique astigmatism (0.06 D @ 34.5 ); the $2 \mathrm{~mm}$ apex/zone showed the lowest difference between TK and TCA in eyes with WTR astigmatism (0.19 D @ 35.6 $)$.

Table 5 shows the mean vectorial values of astigmatism measurements given by the two devices. The only statistically significant differences were observed for $\mathrm{KP}(45)$ vectors in ATR and WTR eyes, meaning a difference in the orientation of astigmatism.

\section{Discussion}

Our data show a high repeatability of both $\mathrm{K}$ and TK values, as measured by the IOLMaster 700. The most important finding is that the repeatability of TK is as high as the repeatability of $\mathrm{K}$ in both unoperated and post-LASIK eyes. The relevance of TK is mainly related to the IOL power calculation in post-refractive surgery and in astigmatic eyes [9, 10, 12]. By taking the posterior corneal curvature into account, TK (unlike K) does not make any assumption about the anterior to posterior curvature ratio, which leads to the so-called "index of refraction error" in post-LASIK eyes [27], and reduces the overestimation of WTR astigmatism and the underestimation of ATR astigmatism.

The high repeatability of TK in unoperated eyes reported in this study confirms previous finding on 93 healthy 
volunteers (mean age $=52$ years; range $=18-85$ years), even if we observed a slightly higher $S_{\mathrm{w}}$ (probably related to the older age of the our sample, which may lead to a lower degree of cooperation) [28]. As regard other instruments, the $S_{\mathrm{w}}$ of TK in our study ( $\left.0.09 \mathrm{D}\right)$ lies between the values previously obtained by Aramberri et al. for the TCP measured by a rotating Scheimpflug camera (Pentacam HR, Oculus) and a dual Scheimpflug analyzer (Galilei G2, Port, Ziemer); they reported values of 0.05 and $0.12 \mathrm{D}$, respectively, in a sample of young patients (mean age $=35$ years) [24]. However, comparison between studies have to be taken with caution due to the different study populations; measurements in older patients with cataract usually show a worse repeatability than those in young healthy subjects [13]. The main advantage compared to the TCP measured by the Scheimpflug systems is that TK can be directly entered into IOL power formulas, since in unoperated eyes its mean value $(43.18 \pm 1.37 \mathrm{D})$ does not show any clinically significant difference compared to standard $\mathrm{K}$ $(43.14 \pm 1.37 \mathrm{D})$, as was previously found also by Srivannaboon et al [9]. Moreover, the maximum difference between $\mathrm{K}$ and TK in unoperated eyes is never higher than a quarter of a diopter. In contrast, the TCP measured by any Scheimpflug camera is lower compared to $\mathrm{K}$ and requires specifically optimized constants $[4,19,26,29]$.

We also aimed to assess whether the repeatability of $\mathrm{K}$ and TK decreased in post-LASIK eyes, as ocular surface changes may affect the quality of measurements (the repeatability of simulated $\mathrm{K}$ has been reported to be lower after excimer laser with both Scheimpflug and OCT systems) $[19,26]$. However, we observed that the repeatability was slightly better: this finding may depend on the different population of unoperated and post-LASIK patients (rather than on the corneal conditions), as post-LASIK patients are younger and thus able to maintain better fixation. Interestingly, we observed that, in eyes with previous myopic surgery, the difference between $\mathrm{K}$ and TK was correlated to the magnitude of $\mathrm{K}$ : the lower the $\mathrm{K}$, the larger the difference. This is due to the fact that, after myopic PRK or LASIK, corneal power is overestimated by $\mathrm{K}$; the overestimation is greater for higher degrees of myopic correction.

As regards the repeatability of $\mathrm{K}$ in unoperated eyes, several authors had already reported that the values measured by the IOLMaster 700 show high repeatability, with $S_{\mathrm{w}}$ ranging between 0.07 and $0.13 \mathrm{D}$ [30-32]. A similar repeatability was reported for two optical biometers with a Placido disc, the Aladdin (Topcon Europe, Florence, Italy) and the OA-2000 (Tomey, Nagoya, Japan), whose values of $S_{\mathrm{w}}$ for K were 0.09 and $0.06 \mathrm{D}$, respectively [33, 34]. The repeatability of $\mathrm{K}$ measurements $\left(S_{\mathrm{w}}=0.09 \mathrm{D}\right)$ by the Lenstar (Haag-Streit, Bern, Switzerland) was also close to that found in the present study [32]. If we specifically consider cataract patients, the repeatability of $\mathrm{K}(0.08 \mathrm{D})$ and TK $(0.09 \mathrm{D})$ was better than the repeatability of $\mathrm{K}$ as measured by the Pentacam AXL $\left(\mathrm{Sw}_{\mathrm{w}}=0.13 \mathrm{D}\right)$ and the Allegro Biograph $\left(S_{\mathrm{w}}=0.16 \mathrm{D}\right)$, which is a rebranded LenStar [13]. Of course, data from different studies should be compared to caution, since they are influenced by the different populations analysed and the different environmental conditions.

Astigmatism analysis showed a good repeatability in both groups (the ICC of magnitude, axis and both vectors was $>0.9$ ), although to a slightly lesser extent compared to steep, flat, and average corneal power measurements, as also found by other authors who reported lower repeatability for astigmatism compared to average corneal power [15, 17, 24]. The repeatability was worse for eyes with lower amounts of astigmatism, in agreement with the results reported by Kim et al [17]. In unoperated eyes, the $S_{\mathrm{w}}$ of the K $(0.13 \mathrm{D})$ and TK $(0.14 \mathrm{D})$ astigmatism magnitude was similar to or better than that previously reported for other instruments, such as the LenStar $\left(S_{\mathrm{w}}=0.13\right)$, the Cassini (i-Optics, the Netherlands, $\left.S_{\mathrm{w}}=0.31\right)$ and the Galilei G4 $(0.18 \mathrm{D})[15,17]$.

Vectorial analysis in unoperated eyes confirmed that, compared to TK, $\mathrm{K}$ underestimates corneal astigmatism in eyes with ATR astigmatism and overestimates it in eyes with WTR astigmatism. This result, which has not been previously reported in relation to measurements by the IOLMaster 700, mirrors previous experiences with other technologies measuring posterior and TCA [35-37]. Moreover, a comparison with the TCA measurements by the Pentacam AXL revealed clinically significant differences (mainly due to the $\mathrm{KP}(45)$ vector, i.e., to the torsional effect of astigmatism). Hence, as previously observed, TCA measurements provided by the two devices cannot be considered interchangeable [28]. We can speculate that these discrepancies are related to the different methods used to calculate TCA, since previous studies did not find significant differences between the two devices in the measurement of keratometric astigmatism [38, 39]. An analysis of a larger sample is warranted in this regard, since the comparison was performed on only a few eyes.

This study has some limitations. First, we did not investigate repeatability in specific conditions, such as keratoconus, for which further investigations are necessary. Second, we did not assess the accuracy of $\mathrm{K}$ and TK for IOL power calculation in unoperated eyes: this issue, which has already been evaluated in a few relatively small studies $[9,11]$, will be the subject of future projects involving a larger sample. Third, the comparison of the TCA by the two devices was performed on a relatively low number of cases. However, our results agree with a previous larger study [25].

In conclusion, our data support the high repeatability of $\mathrm{K}$ and TK measurements by the IOLMaster 700 in both 
unoperated eyes and post-excimer laser surgery eyes. When compared to conventional $\mathrm{K}$, TK confirmed to provide similar spherical equivalent measurements in unoperated eyes, lower spherical equivalent measurements in postmyopic laser surgery eyes and different astigmatism measurements. Moreover, TCA provided by total keratometry and Scheimpflug imaging are not interchangeable.

\section{Summary}

\section{What was known before}

- Total Keratometry (from both corneal surfaces) and standard Keratometry (from anterior corneal surface only) by IOLMaster show on average similar values in unoperated eyes.

\section{What this study adds}

- Total Keratometry measurements show high repeatability in both unoperated and post-LASIK eyes. Such repeatability is as high as the repeatability of standard keratometry.

- Total corneal astigmatism, as measured by Total Keratometry, is different compared to total corneal astigmatism measured by a Scheimpflug camera.

\section{Acknowledgements}

Funding The contribution of I.R.C.C.S. - G.B. Bietti Foundation was supported by Fondazione Roma and the Italian Ministry of Health

\section{Compliance with ethical standards}

Conflict of interest KJH licenses the registered trademark name Hoffer to ensure accurate programming of his formulas to Carl ZeissMeditec (IOLMasters), Haag-Streit (LenStar/EyeStar), Heidelberg Engineering (Anterion), Oculus (Pentacam AXL), Movu (Argos), Nidek (AL-Scan), Oculus (Pentacam AXL), Tomey (OA-2000), Topcon EU/VisiaImaging (Aladdin), Ziemer (Galilei G6) and all Ascan biometer manufacturers. GS is a consultant to CSO and has received personal fees from Alcon, Oculus, and Zeiss. For the remaining authors none were declared.

Publisher's note Springer Nature remains neutral with regard to jurisdictional claims in published maps and institutional affiliations.

\section{References Further Reading}

1. Gutmark R, Guyton DL. Origins of the keratometer and its evolving role in ophthalmology. Surv Ophthalmol. 2010;55:481-97.
2. Savini G, Hoffer KJ, Schiano-Lomoriello D, Ducoli P. Simulated keratometry versus total corneal power by ray tracing: a comparison in prediction accuracy of intraocular lens power. Cornea. 2017;36:1368-72.

3. Savini G, Barboni P, Carbonelli M, Hoffer KJ. Accuracy of corneal power measurements by a new Scheimpflug camera combined with Placido-disk corneal topography for intraocular lens power calculation in unoperated eyes. J Cataract Refract Surg. 2012;38:787-92.

4. Savini G, Barboni P, Carbonelli M, Hoffer KJ. Comparison of methods to measure corneal power for intraocular lens power calculation using a rotating Scheimpflug camera. J Cataract Refract Surg. 2013;39:598-604.

5. Saad E, Shammas MC, Shammas HJ. Scheimpflug corneal power measurements for intraocular lens power calculation in cataract surgery. Am J Ophthalmol. 2013;156:460-7.

6. Næser K, Savini G, Bregnhøj JF. Corneal powers measured with a rotating Scheimpflug camera. $\mathrm{Br}$ J Ophthalmol. 2016;100: 1196-1200.

7. Shirayama M, Wang L, Koch DD, Weikert MP. Comparison of accuracy of intraocular lens calculations using automated keratometry, a Placido- based corneal topographer, and a combined Placido-based and dual Scheimpflug corneal topographer. Cornea. 2010;29:1136-8.

8. Savini G, Barboni P, Carbonelli M, Hoffer KJ. Accuracy of a dual Scheimpflug analyzer and a corneal topography system for intraocular lens power calculation in unoperated eyes. J Cataract Refract Surg. 2011;37:72-6.

9. Srivannaboon S, Chirapapaisan C. Comparison of refractive outcomes using conventional keratometry or total keratometry for IOL power calculation in cataract surgery. Graefes Arch Clin Exp Ophthalmol. 2019;257:2677-82.

10. LaHood BR, Goggin M, Beheregaray S, Andrew NH, Esterman A. Comparing total keratometry measurement on the IOLMaster 700 with Goggin nomogram adjusted anterior keratometry. J Refract Surg. 2018;34:521-6.

11. Fabian E, Wehner W. Prediction accuracy of total keratometry compared to standard keratometry using different intraocular lens power formulas. J Refract Surg. 2019;35:362-8.

12. Wang L, Spektor T, de Souza RG, Koch DD. Evaluation of total keratometry and its accuracy for intraocular lens power calculation in eyes after corneal refractive surgery. J Cataract Refract Surg. 2019;45:1416-21.

13. Ruiz-Mesa R, Abengózar-Vela A, Ruiz-Santos M. Comparison of a new Scheimpflug imaging combined with partial coherence interferometry biometer and a low-coherence reflectometry biometer. J Cataract Refract Surg. 2017;43:1406-12.

14. Næser K. Assessment and statistics of surgically induced astigmatism. Acta Ophthalmol Scand. 2008;86:1-28.

15. Ventura BV, Al-Mohtaseb Z, Wang L, Koch DD, Weikert MP. Repeatability and comparability of corneal power and corneal astigmatism obtained from a point-source color light-emitting diode topographer, a Placido-based corneal topographer, and a low-coherence reflectometer. J Cataract Refract Surg. 2015;41:2242-50.

16. Kobashi H, Kamiya K, Igarashi A, Ishii R, Sato N, Wang G, et al. Comparison of corneal power, corneal astigmatism, and axis location in normal eyes obtained from an autokeratometer and a corneal topographer. J Cataract Refract Surg. 2012;38:648-54.

17. Kim EJ, Montes de Oca I, Wang L, Weikert MP, Koch DD, Khandelwal SS. Repeatability of posterior and total corneal curvature measurements with a dual Scheimpflug-Placido tomographer. J Cataract Refract Surg. 2015;41:2731-8.

18. International Organization for Standardization. Accuracy (trueness and precision) of measurement methods and results. Part 1. General principles and definitions. Geneva: ISO; 1994. (ISO 5725-1:1994). 
19. Savini G, Schiano-Lomoriello D, Hoffer KJ. Repeatability of automatic measurements by a new anterior segment optical coherence tomographer combined with Placido topography and agreement with 2 Scheimpflug cameras. J Cataract Refract Surg. 2018;44:471-8.

20. Bland JM, Altman DG. Statistical methods for assessing agreement between two methods of clinical measurement. Lancet. 1986;1:307-10.

21. Budenz DL, Fredette MJ, Feuer WJ. Reproducibility of peripapillary retinal nerve fiber thickness measurements with stratus OCT in glaucomatous eyes. Ophthalmology. 2008;115:661-6.

22. McGraw KO, Wong SP. Forming inferences about some intraclass correlation coefficients. Psychol Methods. 1996;1:30-46.

23. McAlinden C, Khadka J, Pesudovs K. Precision (repeatability and reproducibility) studies and sample-size calculation. J Cataract Refract Surg. 2015;41:2598-604.

24. Aramberri J, Araz L, Garcia A, Illarramendi I, Olmos J, Oyanarte I, et al. Dual versus single Scheimpflug camera for anterior segment analysis: precision and agreement. J Cataract Refract Surg. 2012;38:1934-49.

25. Shirayama M, Wang L, Weikert MP, Koch DD. Comparison of corneal powers obtained from 4 different devices. Am J Ophthalmol. 2009;148:528-35.

26. Savini G, Barboni P, Carbonelli M, Hoffer KJ. Repeatability of automatic measurements by a new Scheimpflug camera combined with Placido topography. J Cataract Refract Surg. 2011;37:1809-16.

27. Hoffer KJ. Intraocular lens power calculation after previous laser refractive surgery. J Cataract Refract Surg. 2009;35:759-65.

28. Shajari M, Sonntag R, Ramsauer M, Kreutzer T, Vounotrypidis E, Kohnen T, et al. Evaluation of total corneal power measurements with a new optical biometer. J Cataract Refract Surg. 2020;46:675-81.

29. Savini G, Negishi K, Hoffer KJ, Schiano, Lomoriello D. Refractive outcomes of intraocular lens power calculation using different corneal power measurements with a new optical biometer. J Cataract Refract Surg. 2018;44:701-8.

30. Jung S, Chin HS, Kim NR, Lee KW, Jung JW. Comparison of repeatability and agreement between swept-source optical biometry and dual-Scheimpflug topography. J Ophthalmol. 2017;2017:1516395
31. Lu W, Li Y, Savini G, Song B, Hu Q, Wang Q, et al. Comparison of anterior segment measurements obtained using a swept-source optical coherence tomography biometer and a ScheimpflugPlacido tomographer. J Cataract Refract Surg. 2019;45:298-304.

32. Kurian M, Negalur N, Das S, Puttaiah NK, Haria D, TS J, et al. Biometry with a new swept-source optical coherence tomography biometer: repeatability and agreement with an optical lowcoherence reflectometry device. J Cataract Refract Surg. 2016;42:577-81.

33. Huang J, Savini G, Wu F, Yu X, Yang J, Yu A, et al. Repeatability and reproducibility of ocular biometry using a new noncontact optical low-coherence interferometer. J Cataract Refract Surg. 2015;41:2223-41.

34. Huang J, Savini G, Hoffer KJ, Chen H, Lu W, Hu Q, et al. Repeatability and interobserver reproducibility of a new optical biometer based on swept-source optical coherence tomography and comparison with IOLMaster. $\mathrm{Br} \mathrm{J}$ Ophthalmol. 2017;101:493-8.

35. Koch DD, Ali SF, Weikert MP, Shirayama M, Jenkins R, Wang L. Contribution of posterior corneal astigmatism to total corneal astigmatism. J Cataract Refract Surg. 2012;38:2080-7.

36. Tonn B, Klaproth OK, Kohnen T. Anterior surface-based keratometry compared with Scheimpflug tomography-based total corneal astigmatism. Investig Ophthalmol Vis Sci. 2015;56:291-8.

37. Savini G, Versaci F, Vestri G, Ducoli P, Næser K. Influence of posterior corneal astigmatism on total corneal astigmatism in eyes with moderate to high astigmatism. J Cataract Refract Surg. 2014;40:1645-53.

38. Özyol P, Özyol E. Agreement between swept-source optical biometry and Scheimpflug-based topography measurements of anterior segment parameters. Am J Ophthalmol. 2016;169:73-78.

39. Shajari M, Cremonese C, Petermann K, Singh P, Müller M, Kohnen T. Comparison of axial length, corneal curvature, and anterior chamber depth measurements of 2 recently introduced devices to a known biometer. Am J Ophthalmol. 2017;178:58-64. Other cited material

Dupont WD, Plummer WD Jr. PS: Power and Sample Size Calculation, version 3.0, 2009. Nashville, TN, Department of Biostatistics, Vanderbilt University, 2012. Available at: http://biostat.mc. vanderbilt.edu/twiki/bin/view/Main/PowerSampleSize. Accessed March 14th, 2020. 